\title{
Stallion Mate Choice and Mare Sexual Behaviour in a Herd of Sorraia Horses (Equus caballus)
}

\author{
Filipa Paiva Brandão Deslandes Heitor and Luís António Matos Vicente \\ Centro de Biologia Ambiental, Faculdade de Ciências, Universidade de Lisboa, Campo Grande, Edifício C2, \\ 1749-016 Lisboa, Portugal \\ Correspondence should be addressed to Filipa Paiva Brandão Deslandes Heitor, heitor.filipa@gmail.com
}

Received 26 January 2011; Accepted 20 March 2011

Academic Editor: M. Sarà

Copyright @ 2011 F. P. B. D. Heitor and L. A. M. Vicente. This is an open access article distributed under the Creative Commons Attribution License, which permits unrestricted use, distribution, and reproduction in any medium, provided the original work is properly cited.

\begin{abstract}
We examined the relationship between male mate choice, female sexual behaviour, and individual factors in a managed group of Sorraia horses. The herd comprised 9-11 adult mares and their foals. Two stallions were introduced into the mare group in different years for pasture breeding. Mare receptivity during oestrus was poorly correlated with individual factors. Stallions did not prefer to mate with mares that showed the greatest behavioural receptivity during oestrus. The older and more experienced stallion preferred to mate with the older, higher-ranking, or barren oestrous mares. The younger stallion preferred to mate with the more genetically related mares and showed higher oestrus discrimination of mares to who he kept proximity during oestrus. Mate choice was not associated with probability of foaling in the following year. The differential influence of individual factors on mate choice between the stallions could stem from differences in breeding experience and familiarity with the mares.
\end{abstract}

\section{Introduction}

The Sorraia horse is a Portuguese autochthonous breed which is believed to be a direct descendant from the primitive South Iberian horse [1]. The population currently includes less than 200 individuals, which are mainly located in Portugal and Germany and presents high inbreeding levels [1]. Due to its small effective number, that includes less than 100 brood mares, the Sorraia horse is considered to be at critical-maintained risk status by FAO [2]. A breeding management plan is necessary to minimize inbreeding and preserve genetic variation of the population [1]. In order to implement such breeding management plan and increase the effective number of the Sorraia horse population, it is important to know the factors that affect sexual behaviour and its impact on reproductive success.

Feral band stallions defend the mare group and their mating opportunities from other males year round, as is typical of female defence polygyny [3-6]. Unlike feral stallions, Sorraia stallions are kept in managed mare groups at pasture during the reproductive season and cannot choose group members. However, Sorraia stallions can choose who to mate with, and opportunity for mate choice arises when more than one female is in oestrus.

Mares are seasonally polyestrous, cyclically showing periods of oestrus and dioestrus during spring and summer, and experiencing a prolonged anoestrus during fall and winter [7]. Stallions may not mate with all mares when they come into oestrus simultaneously [8] and show preference for certain females with whom they mate repeatedly [9-11]. Factors such as mare coat colour, size, days from ovulation, lactation status, age, and dominance rank are known to affect sexual preferences $[7,10]$.

The stallion may use cues such as age, rank, or reproductive state to assess a mare's future ability to raise a foal. Mare age is an important factor for foal survival because older mothers target their investment better due to experience and are more successful at raising offspring [12]. Higherranking mares may benefit from higher quality diets, produce faster growing offspring [13], and their foals may be more protected against aggression $[14,15]$. Maternal care entails costs in terms of immediate loss of body condition which translates into decreased conception rates and costs to future reproduction $[12,16]$. Therefore, mares that foal on a given 
year may have lower probability of conceiving or reduced ability to invest in offspring in the following year.

Female sexual behaviour and receptivity during oestrus are also related to individual factors. As mares get older, sexual experience increases and residual reproductive value decreases [12]. Older and more experienced mares are usually more receptive [17]. The dominance status of females relative to the stallion may also be relevant, as Przewalski's stallions are sometimes rejected by mares dominant to them and fail to breed them [18]. Barren mares may show greater receptivity than mares with foals [11].

Mares avoid mating with familiar males, who are usually close relatives, and prefer to join bands with unfamiliar males after natal dispersal, which functions to prevent inbreeding [19-21]. Therefore, stallions could prefer to mate with mares that are less genetically related to him, and mares that are more genetically related to the stallion could be less receptive to his mating attempts.

Male mate choice could also be aimed at reducing mating effort (e.g., time, energy, and risk of injury). Mares play an important role in sexual stimulation and timing of copulation $[22,23]$. Therefore, females that solicit the stallion during oestrus more often or more overtly may be preferred mating partners $[8,9]$ because mating with them requires lower effort and oestrus detection is improved.

We conducted behavioural observations on one of the largest Sorraia horse subpopulations in Portugal, to test the following specific hypotheses: (1) oestrous mares that are older, less genetically related to the stallion, subordinate, or barren display greater sexual activity towards the stallion; (2) the stallion chooses to mate with the oldest, highest-ranking, least genetically related, subordinate or barren mares among oestrous females; (3) the stallion chooses to mate with mares that show greatest sexual activity towards him among oestrous females; (4) male mate choice is associated with probability of foaling in the following year.

\section{Methods}

2.1. Subjects and Study Site. Observations were conducted on a pastured group of Sorraia horses kept at Alter studfarm $\left(39^{\circ} 11^{\prime} \mathrm{N}, 7^{\circ} 39^{\prime} \mathrm{W}\right)$, Portugal, in 2003 and 2005 . The herd comprised 9-11 adult mares and their foals. Mares ranged in age from 4 to 22 years and had known each other since birth. Each year, a different stallion was introduced into the mare group in February, and remained there until June for pasture breeding. In 2003, the stallion was 11 years old and had been used for reproduction in this herd since 2001. In 2005, a 5-year-old stallion was used for the first time and therefore was unacquainted with the mares when he entered the group. Both stallions and mares were experienced in pasture breeding, which was implemented since 1998. Six foals were born in 2003 and seven foals were born in 2005, but three died within few hours or days after birth in each year. Shortly after the beginning of observations in 2005, a mare died a few weeks after a miscarriage and was excluded from analysis. Foals were weaned and removed from the herd at approximately nine months of age.
The herd occupied two 5.5 and 17.2 ha pastures enclosed by $1.5-\mathrm{m}$ high wire fences and walls and fed mainly on grasses. Horses had access to supplemental feed in summer and veterinary care. Water was available from temporary water lines, watering ponds and canals connected to reservoirs. Animals were taken to a paddock a few times per year for pregnancy detection, foal removal, branding, tail and mane shearing, and collection of blood samples for paternity analyses.

2.2. Data Collection. Behavioural observations were conducted on foot, 3-10 m from the horses, between 06:30 and 18:30 h solar time. We collected data on social interactions during a series of 25-min focal samples [24] randomly assigned to the subjects. For every interaction, the type of behaviour, initiator, and receiver(s), reaction of the receiver(s), and context were noted. Sexual interactions consisted of courting behaviours (approach, follow, and body contacts), presenting to the stallion, mounting, and copulation. Copulation was recorded when the stallion gained intromission, performed several pelvic thrusts, remained stationary on the mare for a short period of time and finally dismounted with loss of erection [22]. Agonisticrelated interactions included displacements, mild threats, bite threats, bites, kick threats, kicks, chases, attacks, and herding (descriptions are presented elsewhere [25]). In 2005, we recorded approaches across one body-length distance, the identity of the focal animal's nearest neighbour (relative to the closest body part) and of its associates (horses within one body-length) by instantaneous sampling at 5 -min intervals [24].

This study was part of a broader research project on social relationships of Sorraia horses. We conducted $206 \mathrm{~h}$ of focal sampling on both stallion and mares over $316 \mathrm{~h}$ of observation in 2003, and $42 \mathrm{~h}$ of focal sampling on the stallion over $188 \mathrm{~h}$ of observation in 2005. The difference between observation time and focal sampling time corresponds to ad libitum sampling. As sexual behaviours occurred at low frequencies, ad libitum data collected throughout the project in 2003 and 2005 were also included in statistical analyses. Mare body condition was estimated in 2005, according to a scale which varies from 0 (very thin) to 5 (obese), with half point gradations [26].

2.3. Data Analysis. Observation days when each female was in oestrus or dioestrus were determined according to her reproductive state (pregnant mares were not in oestrus [27]) and estimated conception date (obtained by subtracting the average gestation period of 336 days to foal birth date in the following year [17]), in conjunction with criteria adapted from Asa et al. [28] and Waring [7] described below. A mare was classified as being in oestrus on a given day if at least one of the following signs of oestrus were recorded: (1) she initiated sexual behaviours at least once; (2) when receiving sexual behaviours from the stallion, she remained calm, with raised tail and one of the following components: (i) straddled hind legs, (ii) clitoral winking, (iii) voiding small amounts of urine; (3) copulation. If no copulation 
was recorded and the mare directed agonistic interactions or moved away from the stallion when sexually approached by him, we concluded she was not in oestrus. Intervals of 1-3 days with missing data between oestrus days, as assessed by the previous criteria, were also considered to be oestrus days.

Sexual behaviours were analysed at the level of the "mating attempt", which was defined as a behavioural sequence that includes one or more sexual behaviours. We considered the following categories of mare reactions to mating attempts:

(i) positive: raised tail, straddled hind legs, clitoral winking, voiding small amounts of urine, or affiliative interactions;

(ii) negative: avoid, withdraw or agonistic interactions;

(iii) ambivalent: showing behaviours included both in the positive and negative categories;

(iv) neutral: includes all other reactions (e.g., look at the stallion, vocalizations).

We computed the following measures of female sexual activity: proximity to the stallion during oestrus (only in 2005), receptivity and frequency of sexual behaviours initiated by the mare. Proximity of mares to the stallion during oestrus periods was measured by the time spent as associate and nearest neighbour to him (i.e., estimated by the percentage of instantaneous samples as associate or nearest neighbour) and by the frequency of approaches given to the stallion and received from the stallion by mares. Receptivity was measured as the percentage of positive reactions to mating attempts received from the stallion during oestrus.

We examined three parameters of sexual behaviour associated with male mate choice: frequency of mating attempts, mating success, and oestrus discrimination. We computed the frequency of mating attempts directed to oestrous mares, during total oestrus time and during days when several mares were in oestrus simultaneously. Mating success was measured as the percentage of mating attempts with copulation, during oestrus and during the whole study (i.e., total success). We attributed the cause of the lack of success of a mating attempt to combinations of the following observed reactions: avoidance (mare moves away from the stallion), aggression (mare directs agonistic interactions to the stallion), interference (another mare directs an interaction to the stallion and/or the mare), and quit (termination by the stallion). Oestrus discrimination was computed as the number of mating attempts directed to a mare during oestrus, divided by the total number of mating attempts directed by the stallion to that mare over the whole study. Frequencies of mating attempts were computed from focal sampling data. Receptivity, mating success, oestrus discrimination scores, and cause of unsuccessful mating attempts were estimated from the complete data set (focal and ad libitum data).

Dominance relationships were determined on the basis of agonistic-related interactions. We excluded kicks and kick threats due to their defensive function [29, 30]. Herding was also excluded because it was performed only by the stallion. The dominant individual within a dyad was the one that initiated the majority of agonistic-related interactions that caused a submissive response from the other animal. We measured linearity of mare dominance relationships by Kendall's coefficient of consistence $K$, based on the number of circular triads, $d[31,32]$. Linearity was significant in both years (2003: $K=0.85, d=6, N=10, P<.02 ; 2005$ : $K=0.93, d=3, N=10, P<.03)$ and therefore mares were ordered in a linear hierarchy by the "I and SI" method [33]. An ordinal dominance rank, which increased from the bottom to the top of the hierarchy, was then assigned to each female.

Kinship coefficient between the stallion and the mares was computed from pedigree data up to the founder animals.

Spearman's rank correlation coefficient was used to assess the relationship between sexual behaviour patterns and mare individual factors: age, rank, and kinship relative to the stallion. Frequency of mating attempts directed to the oldest, highest-ranking, or least genetically related mare among those in oestrous was compared with the mean frequency directed to other simultaneous oestrous mares by means of Wilcoxon paired-sample tests. We tested for differences in sexual behaviours patterns between dominants and subordinates to the stallion and between mares that were in different reproductive states (foaled versus barren) by means of Mann-Whitney $U$-test. Mares whose foals died soon after birth were treated as barren.

All statistical tests were one-tailed and the significance level was set at 0.05 . Standard statistical tests were performed on Statistica 5.1 StatSoft, Inc.

\section{Results}

The stallion in 2003 was dominant over two mares, which occupied ranks 2 and 6 in the mare dominance hierarchy. The stallion in 2005 was dominant over three mares: the oldest, a 13-year-old, and the youngest female (ranks 5, 4, and 1 , resp.).

Barren mares were all in better body condition (range: 2.5-3) than mares with foals (range: 1-1.5) in 2005. Every mare came into oestrus during the study period, except the third highest-ranking female in 2003. There was at least one female in oestrus during 35 of the $60(58.3 \%)$ observation days in 2003, and during 31 of the 57 (54.4\%) observation days in 2005. Two or more mares were simultaneously in oestrus in $19(54.3 \%)$ of the 35 oestrus days in 2003 (mean 2.16, maximum 3 mares per day), and in 11 (35.5\%) of the 31 oestrus days in 2005 (mean 2.36, maximum 4 mares per day). Therefore, the two stallions had similar opportunities for mate choice.

The stallion in 2003 copulated with seven out of nine mares $(77.8 \%)$ and the stallion in 2005 was observed copulating with five out of 10 mares (50\%). Five copulations were recorded during focal samples in 2003 (49 copulations in the complete data set) and four copulations in 2005 (25 copulations in the complete data set). Copulation frequency (mean \pm S.D.) was $0.013 \pm 0.017 \mathrm{~h}^{-1}$ per mare in 2003 $\left(0.090 \pm 0.100 \mathrm{~h}^{-1}\right.$ per mare during oestrus time $)$ and 0.010 $\pm 0.024 \mathrm{~h}^{-1}$ per mare in $2005\left(0.061 \pm 0.130 \mathrm{~h}^{-1}\right.$ per mare 
TABLE 1: Cause of unsuccess of mating attempts.

\begin{tabular}{lcc}
\hline Cause of unsuccess (\%) & 2003 & 2005 \\
\hline Avoidance & 6.8 & 4.2 \\
Aggression & 23.6 & 12.6 \\
Interference & 33.8 & 20.2 \\
Quit & 26.2 & 44.5 \\
Avoidance + aggression & 2.1 & 4.2 \\
Avoidance + interference & 3.8 & 7.6 \\
Aggression + interference & 3.0 & 4.2 \\
Quit + interference & 0 & 0.8 \\
Avoidance + aggression + interference & 0.8 & 1.7 \\
\hline Total number of mating attempts & 237 & 119 \\
\hline
\end{tabular}

during oestrus time). The main cause of unsuccess (Table 1) was "interference" in 2003 (33.8\%) and "quit" in 2005 $(44.5 \%)$. The stallions had similar oestrus discrimination scores and frequencies of mating attempts, but the stallion in 2003 had higher mating success (Table 2). Frequency of mating attempts during oestrus was not significantly correlated with mating success during oestrus in either year (2003: $r_{\mathrm{s}}=0.24, N=8, P>.05 ; 2005: r_{\mathrm{s}}=-0.32, N=10$, $P>.05)$.

\subsection{Influence of Individual Factors on Female Sexual Activity.} Oestrous subordinate mares spent more time as the stallion nearest neighbour than oestrous dominant mares, as predicted (Table 3). However, this difference was probably due to stallion behaviour rather than mare behaviour, because the stallion approached subordinates significantly more often than he approached dominants (Table 3). Barren mares made a greater effort to keep proximity to the stallion during oestrus than mares that foaled (Table 3). Contrary to our predictions, younger mares spent more time as the stallion's associates and approached him more frequently than older mares during oestrus periods (Table 4). Moreover, mares that were more genetically related to the stallion spent more time as his associates during oestrus than the less related mares (Table 4).

During oestrus periods in 2003, mares showed 55.3 $\pm 23.0 \%$ positive, $15.3 \pm 19.7 \%$ negative, $14.9 \pm 8.0 \%$ ambivalent, and $14.9 \pm 8.0 \%$ neutral reactions (mean \pm S.D.) to mating attempts. The stallion in 2005 received less negative reactions from oestrous mares than the stallion in 2003 (mean \pm S.D.): $57.9 \pm 23.0 \%$ positive, $5.8 \pm 11.0 \%$ negative, $13.5 \pm 15.8 \%$ ambivalent, and $22.9 \pm 16.0 \%$ neutral. Subordinate and barren females were not more receptive during oestrus in either year (Table 2). Age, rank and kinship were also unrelated to receptivity (Table 5).

We could not analyse the influence of individual factors on the frequency of mating attempts initiated by mares, because mares initiated them only once each year during focal samples. Considering both focal and ad libitum data, eight attempts in 2003 and five attempts in 2005 were initiated by mares. Mare presentations to the stallion were observed only in 2005: five times in focal data and seven times in ad libitum data. The stallion responded sexually to mare presentations only twice in ad libitum data.

\subsection{Influence of Individual Factors on Male Mate Choice.} Dominance relationships with the stallion were not related to frequencies of mating attempts in either year (Table 2). The stallion in 2003 attempted to mate more frequently with oestrous barren mares than with oestrous mares with foals, both during the whole reproductive season and during simultaneous oestrous periods, but not the stallion in 2005 (Table 2). Contrary to our predictions, the stallion in 2003 showed greater oestrus discrimination of females dominant to him and reproductive state was not related to oestrus discrimination (Table 2). In 2005, the stallion made higher oestrus discrimination of subordinates and barren mares (Table 2). During simultaneous oestrus periods in 2003, frequency of mating attempts was significantly higher with the oldest and highest-ranking mares (Wilcoxon pairedsample test: $T=7, N=19$ days, $P<.005$; Table 5) but not with the less genetically related mares $(T=51.5$, $N=18$ days, $P>.05$; Table 5). The stallion in 2005 did not show sexual preference for the oldest, highest-ranking, or least genetically related mares (Wilcoxon paired-sample test: age: $T=22, N=11$ days, $P>.05$; rank: $T=20, N=11$ days, $P>.05$; kinship: $T=5.5, N=11$ days, $P>.05$; Table 5). Contrary to our predictions, this stallion directed lower frequencies of mating attempts to the less related mare among those in oestrus. Mating success was not related to individual factors in either year (Tables 2 and 5).

3.3. Influence of Female Sexual Activity on Male Mate Choice. In 2005, oestrus discrimination was significantly higher for mares that the stallion approached more frequently and that spent more time as his nearest neighbour, but frequency of mating attempts and mating success were not related to proximity during oestrus (Table 6).

Mare receptivity was not significantly correlated with oestrus discrimination, frequency of mating attempts, or mating success, neither in 2003 (frequency simultaneous oestrus: $r_{\mathrm{s}}=0.05, N=8, P>.05$; frequency total oestrus: $r_{\mathrm{s}}=0.26, N=8, P>.05$; success in oestrus: $r_{\mathrm{s}}=0.40$, $N=8, P>.05$; oestrus discrimination: $r_{\mathrm{s}}=-0.29, N=8$, $P>.05$ ) nor in 2005 (frequency simultaneous oestrus: $r_{s}=$ $-0.19, N=9, P>.05$; frequency total oestrus: $r_{\mathrm{s}}=0.18$, $N=10, P>.05$; success in oestrus: $r_{s}=-0.07, N=10$, $P>.05$; oestrus discrimination: $\left.r_{s}=0.08, N=10, P>.05\right)$.

3.4. Male Mate Choice and Probability of Foaling. Six of the nine mares in $2003(66.7 \%)$ and two of the 10 mares in $2005(20 \%)$ foaled in the following year. Mares that foaled had not been involved in higher frequencies of mating attempts during oestrus, with higher mating success or higher oestrus discrimination than mares that did not foal in the year following 2003 (Mann-Whitney $U$-test: frequency simultaneous oestrus: $U=8$; frequency total oestrus: $U=6$; success in oestrus: $U=0$; oestrus discrimination: $U=2$; $N_{\mathrm{B}}=2, N_{\mathrm{F}}=6, P>.05$ ) and 2005 (Mann-Whitney $U$-test: frequency total oestrus: $U=4$; success in oestrus: $U=12$; 
TABLE 2: Influence of dominance status and reproductive state on male mate choice and female receptivity, as measured by the MannWhitney $U$-test.

\begin{tabular}{|c|c|c|c|c|c|c|c|}
\hline & \multirow{2}{*}{ Mean \pm S.D. } & \multicolumn{3}{|c|}{ Dominance } & \multicolumn{3}{|c|}{ Reproductive state } \\
\hline & & $N_{\mathrm{D}}$ & $N_{\mathrm{S}}$ & $U$ & $N_{\mathrm{B}}$ & $N_{\mathrm{F}}$ & $U$ \\
\hline \multicolumn{8}{|l|}{2003} \\
\hline Simultaneous oestrus frequency $\left(\mathrm{h}^{-1}\right)$ & $0.91 \pm 0.65$ & 6 & 2 & 10 & 5 & 3 & $15^{*}$ \\
\hline Total oestrus frequency $\left(\mathrm{h}^{-1}\right)$ & $0.72 \pm 0.45$ & 6 & 2 & 10 & 5 & 3 & $15^{*}$ \\
\hline Total success (\%) & $14.9 \pm 11.7$ & 7 & 2 & 6 & 6 & 3 & 11.5 \\
\hline Success in oestrus (\%) & $27.8 \pm 17.1$ & 6 & 2 & 7 & 5 & 3 & 5 \\
\hline Oestrus discrimination (\%) & $74.3 \pm 17.3$ & 6 & 2 & 0 & 5 & 3 & 3 \\
\hline Receptivity (\%) & $55.3 \pm 23.0$ & 6 & 2 & 10 & 5 & 3 & 8 \\
\hline \multicolumn{8}{|l|}{2005} \\
\hline Simultaneous oestrus frequency $\left(\mathrm{h}^{-1}\right)$ & $0.86 \pm 0.57$ & 6 & 3 & 7 & 6 & 3 & 4 \\
\hline Total oestrus frequency $\left(\mathrm{h}^{-1}\right)$ & $0.87 \pm 0.61$ & 7 & 3 & 7.5 & 6 & 4 & 10 \\
\hline Total success (\%) & $10.6 \pm 12.9$ & 7 & 3 & 10 & 6 & 4 & 10 \\
\hline Success in oestrus (\%) & $17.2 \pm 20.4$ & 7 & 3 & 8 & 6 & 4 & 9 \\
\hline Oestrus discrimination (\%) & $72.9 \pm 18.0$ & 7 & 3 & $21^{*}$ & 6 & 4 & $22^{*}$ \\
\hline Receptivity (\%) & $57.9 \pm 23.0$ & 7 & 3 & 8 & 6 & 4 & 17 \\
\hline
\end{tabular}

Number of mares: $N_{\mathrm{D}}$ : dominants, $N_{\mathrm{S}}$ : subordinates, $N_{\mathrm{B}}$ : barren and $N_{\mathrm{F}}$ : with foals; ${ }^{*} P<.05$.

TABLE 3: Influence of dominance status and reproductive state on proximity of mares to the stallion during oestrus, as measured by the Mann-Whitney $U$-test.

\begin{tabular}{|c|c|c|c|c|c|c|c|}
\hline & \multirow{2}{*}{ Mean \pm S.D. } & \multicolumn{3}{|c|}{ Dominance } & \multicolumn{3}{|c|}{ Reproductive state } \\
\hline & & $N_{\mathrm{D}}$ & $N_{\mathrm{S}}$ & $U$ & $N_{\mathrm{B}}$ & $N_{\mathrm{F}}$ & $U$ \\
\hline Associate & $0.10 \pm 0.12$ & 7 & 3 & 13 & 6 & 4 & $21^{*}$ \\
\hline Nearest neighbour & $0.13 \pm 0.10$ & 7 & 3 & $19^{*}$ & 6 & 4 & $22^{*}$ \\
\hline Approaches $\mathrm{r}\left(\mathrm{h}^{-1}\right)$ & $0.19 \pm 0.33$ & 7 & 3 & $21^{*}$ & 6 & 4 & 20 \\
\hline Approaches $\mathrm{g}\left(\mathrm{h}^{-1}\right)$ & $1.01 \pm 0.89$ & 7 & 3 & 15 & 6 & 4 & $22^{*}$ \\
\hline
\end{tabular}

Number of mares: $N_{\mathrm{D}}$ : dominants, $N_{\mathrm{S}}$ : subordinates, $N_{\mathrm{B}}$ : barren, and $N_{\mathrm{F}}$ : with foals; r: received from the stallion, g: given to the stallion; ${ }^{*} P<.05$. Time as associate and as nearest neighbour are expressed as proportions. Frequencies of approaches is measured in number of occurrences per hour.

TABLE 4: Influence of mare age and kinship on proximity to the stallion during oestrus, as assessed by the Spearman's rank correlation coefficient $(N=10)$.

\begin{tabular}{lcc}
\hline & Age & Kinship \\
\hline Associate & -0.89 & 0.57 \\
Nearest neighbour & -0.38 & -0.09 \\
Approaches r & 0.02 & -0.29 \\
Approaches g & -0.77 & 0.43 \\
\hline
\end{tabular}

r: received from the stallion, g: given to the stallion.

oestrus discrimination: $\left.U=5 ; N_{\mathrm{B}}=8, N_{\mathrm{F}}=2, P>.05\right)$. Only one of the two mares that foaled in the year following 2005 had been in oestrus simultaneously with other mares, which precluded statistical tests. The mare that received the highest percentage of copulations in each year (2003: $30.6 \%$ of 49 copulations; 2005 : $52 \%$ of 25 copulations) did not foal in the following year. Moreover, mares that foaled in the following year had not received a higher total number of copulations than those that did not foal $(2003: U=9.5$, $N_{\mathrm{B}}=3, N_{\mathrm{F}}=6, P>.05 ; 2005: U=11, N_{\mathrm{B}}=8, N_{\mathrm{F}}=2$, $P>.05)$.

\section{Discussion}

This study examined four main hypotheses on the relationship between male mate choice, female sexual behaviour, and individual factors in a managed herd of Sorraia horses. The results regarding each hypothesis are discussed below.

4.1. Influence of Individual Factors on Female Sexual Activity. Contrary to our predictions, younger mares and mares that were more genetically related to the younger stallion spent more time in proximity to him during oestrus periods than older and less related mares. Subordinates did not make a greater effort to keep proximity to the stallion than did dominants during oestrus. Nevertheless, the stallion made a greater effort to keep proximity to subordinate females than to dominants during their oestrus periods, possibly because the risk of receiving agonistic interactions from subordinates is lower [25]. As predicted, barren mares spent more time as associates to the stallion and approached him more often during oestrus periods than mares with foals. Barren mares may invest more in future reproduction, whilst mares with foals invest more in current reproduction, which entails greater social isolation after foaling [34]. These findings 
TABLE 5: Influence of mare age, rank, and kinship on sexual behaviour patterns, as assessed by the Spearman's rank correlation coefficient.

\begin{tabular}{lcccccc}
\hline & Simultaneous oestrus frequency & Total oestrus frequency & Total success & Success in oestrus & Oestrus discrimination & Receptivity \\
\hline 2003 & $N=8$ & $N=8$ & $N=9$ & $N=8$ & $N=8$ & $N=8$ \\
Age & $0.69^{*}$ & 0.52 & -0.16 & -0.07 & 0.24 & -0.33 \\
Rank & $0.69^{*}$ & 0.52 & -0.12 & -0.07 & -24 & -0.33 \\
Kinship & 0.16 & 0.06 & -0.03 & -0.29 & -0.17 & -0.51 \\
\hline 2005 & $N=9$ & $N=10$ & $N=10$ & $N=10$ & -10 \\
Age & 0.23 & 0.26 & -0.32 & -0.33 & -0.13 & -0.09 \\
Rank & 0.38 & 0.39 & -0.14 & -0.14 & -0.53 & -0.17 \\
Kinship & 0.19 & 0.41 & 0.46 & 0.39 & & -0.30 \\
\hline
\end{tabular}

${ }^{*} P<.05$

TABLE 6: Influence of proximity of mares to the stallion during oestrus on male mate choice, as assessed by the Spearman's rank correlation coefficient.

\begin{tabular}{lccccc}
\hline & Simultaneous oestrus frequency & Total oestrus frequency & Total success & Success in oestrus & Oestrus discrimination \\
\hline & $N=9$ & $N=10$ & $N=10$ & $N=10$ & $N=10$ \\
Associate & -0.48 & -0.28 & 0.28 & 0.26 & 0.34 \\
Neighbour & -0.56 & -0.63 & 0.14 & 0.15 & $0.82^{*}$ \\
Approaches r & -0.29 & -0.19 & -0.07 & -0.25 & $0.88^{*}$ \\
Approaches g & -0.31 & -0.30 & 0.19 & 0.20 & 0.44 \\
\hline
\end{tabular}

r: received from the stallion, g: given to the stallion; ${ }^{*} P<.05$.

suggest that proximity during oestrus could reflect affiliative and agonistic relationships between the stallion and mares, as well as female sexual activity.

Although mares kept proximity to the stallion during oestrus, sexual behaviours were mostly initiated by the stallion and not by the mares. In contrast, Tyler [3] and McDonnell [23] stated that mares play an active role in initiation of sexual behaviours.

Receptivity was not related to any of the individual factors tested. Consistent with other studies on horses [7, 22, 23, 28], some oestrous mares displayed aggressive or ambivalent reactions to mating attempts and minimal behavioural signs of oestrus. Aggressive behaviours during oestrus could be a mechanism used by dispersing mares in feral populations to test quality of a stallion before joining his band. Resistance behaviours could then function to promote female mate choice $[35,36]$. In managed conditions, although mares cannot choose the stallions that will breed them, resistance behaviours may also be used to assess mate quality.

4.2. Influence of Individual Factors on Male Mate Choice. The two males in our study had similar oestrus discrimination scores and frequencies of mating attempts, but the older stallion had higher mating success than the younger male. Copulation frequency was similar to that reported by Cunha [11] in a previous study of this herd with a different stallion (0.012 copulations $\mathrm{h}^{-1}$ per mare). The younger stallion interrupted almost half his mating attempts for no apparent reason, even when he was not receiving aggression from the mares ("quit"), and despite receiving fewer negative reactions and more neutral reactions from mares than the older stallion did. Perhaps because the younger stallion had less breeding experience and was unacquainted with the mares, he needed to tease them repeatedly to assess oestrus state and attempted to mount a female only when she was clearly receptive. In contrast, the main cause of unsuccess in mating attempts initiated by the older stallion was interference by other mares. Interference behaviours consisted mostly of agonistic interactions directed to the stallion and caused disruption of the sexual behaviour in which he was involved. The functions of sexual interference behaviours are discussed elsewhere by Heitor et al. [37].

The older stallion in this study tried to mate more often with older, higher-ranking, and barren mares, as predicted. Consistent with these findings, Cunha [11] observed that the stallion in a former study of this Sorraia horse herd copulated only with older females and Waring [7] referred that stallions show greater sexual interest in older mares. Asa et al. [28] reported that stallions select the higher-ranking oestrous mare for copulation when more than one oestrous female was present, but Bristol [22] found no such preference. A 15-year-old stallion observed by Steinbjörnsson [8] mated exclusively with barren mares. However, contrary to our predictions, the older stallion showed greater oestrus discrimination of dominant than subordinate females. By targeting better his mating attempts to oestrus periods of dominants, the older stallion could avoid receiving aggression from them.

The younger stallion showed higher oestrus discrimination of subordinate and barren mares, as predicted, but female age and rank did not seem to affect mate choice. Female age and rank were not related to frequency of mating attempts of either stallion in their first year as breeders at Alter studfarm both in the present study and in a previous one [38]. Breeding experience is known to affect 
stallion sexual behaviour [39]. Therefore, the greater general breeding experience and familiarity with the mares of the older stallion before being introduced into the group may have promoted the development of sexual preferences based on mare age, rank, and reproductive state. Future studies should assess whether stallions use these factors as cues to assess female quality or ability to raise foals.

The younger stallion in our study seemed to prefer the most genetically related mares among those in oestrus. Such preference is contrary to our predictions, but it is consistent with sexual patterns of the older stallion in his first year as a breeder in this herd [38]. Cunha [11] found no evidence that a Sorraia stallion avoided copulating with close relatives via the mother (half-sisters). Feral horses do not to avoid mating with close kin per se but with familiar individuals of their natal band, which are usually close relatives [19-21]. In our study, the stallion was unfamiliar with the mares, and he may have chosen the most genetically related mares because they spent more time as his associates during oestrus. However, because both the number of mares that were simultaneously in oestrus per day and the number of days in which there was more than one oestrous female both in the present study and that of Heitor et al. [38] were small, this finding may reflect a spurious relationship and deserves further study.

Contrary to Przewalski's stallions [18], mating success of Sorraia stallions was not lower with dominant females than with subordinates. Therefore, the fact that both stallions were subordinate to the majority of mares did not seem to affect mating success.

\subsection{Influence of Female Sexual Activity on Male Mate Choice.} We found little evidence that male mate choice is aimed at reducing mating effort. Maintaining proximity to the stallion during oestrus did not seem to afford mares with higher frequency of mating attempts or higher mating success. Maintaining proximity to the stallion could have a larger effect on frequency of mating attempts in groups where a higher number of mares are simultaneously in oestrus. Bristol [22] reported that the stallion usually attempted to mate with the mare that was closest to him in a group of 20 pastured mares in synchronized oestrus. In contrast, only 24 Sorraia mares were simultaneously in oestrus per day.

Consistent with our predictions, the younger stallion made greater oestrus discrimination of mares to whom he kept proximity during oestrus. Oestrus discrimination provides an inverse estimate of the level of sexual harassment received by mares when they are not in oestrus. This finding suggests that proximity could reduce the costs associated with sexual harassment (e.g., disruption of other activities, risk of injury).

We did not find a preference in Sorraia stallions for mating with mares that showed the greatest receptivity. In contrast, Ginther [9] observed that stallions copulated repeatedly with the same mares, who were usually the most sexually active. Our study focused on behavioural receptivity, which in some cases does not match ovarian activity [7, $17,28]$. Olfactory cues also play an important role in sexual stimulation of the stallion during courtship $[7,17,39]$.
Although there is no evidence that stallions can detect the oestrus condition of a mare based on olfactory investigation, stallions exhibit the flehmen response to mare urine, which promotes coordination between male and female sexual behaviour [40]. Therefore, stallions probably responded sexually to perceived chemical signs of physiological oestrus, as well as to behavioural signs of oestrus.

4.4. Male Mate Choice and Probability of Foaling. Mate choice was not related to the probability of foaling in the following year. This finding may have several, not mutually exclusive, explanations. The occasional absence of tail flagging at the end of copulations and the occurrence of intervals shorter than the average postejaculatory refractory period of 20 min [28] between copulations suggest that ejaculation was not always achieved by Sorraia stallions. Anovulatory oestrus periods may also have occurred, which are behaviourally undistinguishable from ovulatory oestrus periods $[7,17$, 28]. Moreover, there may have been differences in the frequency of copulation around the time of ovulation, which is the period when mares have the highest probability of conception and occurs within the last two days of oestrus [28]. It has been suggested that stallions may be able to detect the timing of mare ovulation [8], although no evidence that stallions preferred to mate with mares that were closest to ovulation was found [9]. Finally, some mares may have conceived and suffered abortion at an early gestation phase, due to the high inbreeding levels in this herd of Sorraia horses [38]. Future studies on sexual behaviour of Sorraia horses should complement behavioural data with an assessment of physiological variables (e.g., hormone levels) and ovarian activity (e.g., ultrasonography), to measure the extent to which behavioural signs and physiological oestrus match each other and to assess their relative influence on stallion mate choice.

4.5. Final Remarks. In sum, Sorraia stallions do not seem to display similar and consistent patterns of mate choice. The two stallions in this study may have adopted different reproductive strategies: the older stallion may have based mate choice on female quality or ability to raise offspring, whereas the younger stallion may have based mate choice on reduction of mating effort. Moreover, the older stallion had shown different patterns of mate choice in a previous study when compared to the present one. These differences could be related to differences in breeding experience and familiarity with the mares. However, the observed patterns of mate choice could simply be related to particular characteristics and sexual preferences of the two stallions. The low effective number of the Sorraia population and the low number of breeding groups kept at pasture precluded the collection of data on a higher number of stallions in this study. Therefore, more data should be collected on different stallions before conclusions can be drawn regarding the factors that affect stallion mate choice in Sorraia horses.

Mare receptivity during oestrus was poorly correlated with the individual factors tested in this study. Other factors such as individual temperament or physiological variables 
could have a greater influence on behavioural receptivity and deserve further study. In addition, behavioural receptivity did not seem to affect male mate choice. Stallions could rely more on chemical signs of oestrus than behavioural signs because there is large variability in behavioural receptivity during oestrus among mares. In addition, we did not find evidence that mate choice affected the probability of foaling in the following year. Future studies should address the influence of physiological variables and ovarian activity on male mate choice as well as long-term effects of mate choice on female reproductive success.

\section{Acknowledgments}

The authors thank Dr. João Costa Ferreira for permission to conduct this study at Alter studfarm and Dr. Maria do Mar Oom for providing the kinship data. Sónia Emídio participated in data collection. F. Heitor was supported by a Doctoral Fellowship granted by the Fundação para a Ciência e a Tecnologia (SFRH/BD/8792/2002).

\section{References}

[1] C. Luís, The Sorraia horse, a case study of a small and closed population: contribution of molecular markers to the genetic conservation and management of an endangered breed, Ph.D. thesis, University of Lisbon, Lisbon, Portugal, 2006.

[2] B. D. Scherf, World Watch List for Domestic Animal Diversity, Food and Agriculture Organization of the United Nations, Rome, Italy, 3rd edition, 2000.

[3] S. J. Tyler, "The behaviour and social organization of the new forest ponies," Animal Behaviour, vol. 5, no. 2, pp. 87-196, 1972.

[4] R. E. Salter and R. J. Hudson, "Social organization of feral horses in western Canada," Applied Animal Ethology, vol. 8, no. 3, pp. 207-223, 1982.

[5] Y. Kaseda, A. M. Khalil, and H. Ogawa, "Harem stability and reproductive success of Misaki feral mares," Equine Veterinary Journal, vol. 27, no. 5, pp. 368-372, 1995.

[6] W. L. Linklater, E. Z. Cameron, E. O. Minot, and K. J. Stafford, "Stallion harassment and the mating system of horses," Animal Behaviour, vol. 58, no. 2, pp. 295-306, 1999.

[7] G. H. Waring, Horse Behavior: The Behavioral Traits and Adaptations of Domestic and Wild Horses, Including Ponies, Noyes Publications, Park Ridge, NJ, USA, 1983.

[8] B. Steinbjörnsson, "Sexual behavior in herds of Icelandic horses," in Horse Behavior and Welfare. A Dorothy Russell Havemeyer Foundation Workshop, S. McDonnell and D. Mills, Eds., pp. 47-50, Hólar, Iceland, 2002.

[9] O. J. Ginther, "Sexual behaviour following introduction of a stallion into a group of mares," Theriogenology, vol. 19, no. 6, pp. 877-886, 1983.

[10] S. M. McDonnell, "Stallion sexual behavior," in Equine Breeding Management and Artificial Insemination, J. C. Samper, Ed., pp. 53-61, W. B. Saunders, Philadelphia, Pa, USA, 2000.

[11] M. B. Cunha, Comportamento social do Cavalo do Sorraia em regime extensivo, M.S. thesis, Instituto Superior de Psicologia Aplicada, Lisbon, Portugal, 2004.

[12] E. Z. Cameron, W. L. Linklater, K. J. Stafford, and E. O. Minot, "Aging and improving reproductive success in horses: declining residual reproductive value or just older and wiser?"
Behavioral Ecology and Sociobiology, vol. 47, no. 4, pp. 243249, 2000.

[13] P. Duncan, Horses and Grasses: The Nutritional Ecology of Equids and Their Impact on the Camargue, Springer, New York, NY, USA, 1992.

[14] A. T. Rutberg and S. A. Greenberg, "Dominance, aggression frequencies and modes of aggressive competition in feral pony mares," Animal Behaviour, vol. 40, no. 2, pp. 322-331, 1990.

[15] J. W. Weeks, S. L. Crowell-Davis, A. B. Caudle, and G. L. Heusner, "Aggression and social spacing in light horse (Equus caballus) mares and foals," Applied Animal Behaviour Science, vol. 68, no. 4, pp. 319-337, 2000.

[16] D. R. Henneke, G. D. Potter, J. L. Kreider, and B. F. Yeates, "Relationship between condition score, physical measurements and body fat percentage in mares," Equine Veterinary Journal, vol. 15, no. 4, pp. 371-372, 1983.

[17] A. F. Fraser, The Behaviour of the Horse, CAB International, Wallingford, UK, 1992.

[18] L. E. Boyd, “The behaviour of Przewalski's horses and its importance to their management," Applied Animal Behaviour Science, vol. 29, no. 1-4, pp. 301-318, 1991.

[19] P. Duncan, C. Feh, J. C. Gleize, P. Malkas, and A. M. Scott, "Reduction of inbreeding in a natural herd of horses," Animal Behaviour, vol. 32, no. 2, pp. 520-527, 1984.

[20] A. M. Monard and P. Duncan, "Consequences of natal dispersal in female horses," Animal Behaviour, vol. 52, no. 3, pp. 565579, 1996.

[21] A. M. Monard, P. Duncan, and V. Boy, "The proximate mechanisms of natal dispersal in female horses," Behaviour, vol. 133, no. 13-14, pp. 1095-1124, 1996.

[22] F. Bristol, "Breeding behaviour of a stallion at pasture with 20 mares in synchronized oestrus," Journal of Reproduction and Fertility, vol. 32, supplement, pp. 71-77, 1982.

[23] S. M. McDonnell, "Reproductive behavior of stallions and mares: comparison of free-running and domestic in-hand breeding," Animal Reproduction Science, vol. 60-61, pp. 211$219,2000$.

[24] J. Altmann, "Observational study of behavior: sampling methods," Behaviour, vol. 49, no. 3-4, pp. 227-267, 1974.

[25] F. Heitor, M. M. Oom, and L. Vicente, "Social relationships in a herd of Sorraia horses. Part I. Correlates of social dominance and contexts of aggression," Behavioural Processes, vol. 73, no. 2, pp. 170-177, 2006.

[26] C. L. Carroll and P. J. Huntington, "Body condition scoring and weight estimation of horses," Equine Veterinary Journal, vol. 20, no. 1, pp. 41-45, 1988.

[27] C. S. Asa, D. A. Goldfoot, and O. J. Ginther, "Assessment of the sexual behavior of pregnant mares," Hormones and Behavior, vol. 17, no. 4, pp. 405-413, 1983.

[28] C. S. Asa, D. A. Goldfoot, and O. J. Ginther, "Socio-sexual behavior and the ovulatory cycle of ponies (Equus caballus) observed in harem groups," Hormones and Behavior, vol. 13, no. 1, pp. 49-65, 1979.

[29] S. M. Wells and B. von Goldschmidt-Rothschild, "Social behaviour and relationships in a herd of Camargue horses," Zeitschrift für Tierpsychologie, vol. 49, no. 4, pp. 363-380, 1979.

[30] M. C. van Dierendonck, H. de Vries, and M. B. Schilder, "An analysis of dominance, its behavioural parameters and possible determinants in a herd of icelandic horses in captivity," Netherlands Journal of Zoology, vol. 45, no. 3-4, pp. 362-385, 1995.

[31] M. C. Appleby, "The probability of linearity in hierarchies," Animal Behaviour, vol. 31, no. 2, pp. 600-608, 1983. 
[32] H. de Vries, "An improved test of linearity in dominance hierarchies containing unknown or tied relationships," Animal Behaviour, vol. 50, no. 5, pp. 1375-1389, 1995.

[33] H. de Vries, "Finding a dominance order most consistent with a linear hierarchy: a new procedure and review," Animal Behaviour, vol. 55, no. 4, pp. 827-843, 1998.

[34] F. Heitor and L. Vicente, "Affiliative relationships among Sorraia mares: influence of age, dominance, kinship and reproductive state," Journal of Ethology, vol. 28, no. 1, pp. 133-140, 2009.

[35] E. J. A. Cunningham and T. R. Birkhead, "Sex roles and sexual selection,” Animal Behaviour, vol. 56, no. 6, pp. 1311-1321, 1998.

[36] T. Chapman, G. Arnqvist, J. Bangham, and L. Rowe, "Sexual conflict," Trends in Ecology and Evolution, vol. 18, no. 1, pp. 41-47, 2003.

[37] F. Heitor, S. Emídio, and L. Vicente, "Sexual interference behaviour by Sorraia mares (Equus caballus)," in Horses: Biology, Domestication, and Human Interactions, J. E. Leffhalm, Ed., pp. 65-84, Nova Science Publishers, New York, NY, USA, 2011.

[38] F. Heitor, M. M. Oom, and L. Vicente, "Social relationships in a herd of Sorraia horses. Part II. Factors affecting affiliative relationships and sexual behaviours," Behavioural Processes, vol. 73, no. 3, pp. 231-239, 2006.

[39] S. McDonnell, "Reproductive behavior of the stallion," The Veterinary Clinics of North America. Equine Practice, vol. 2, no. 3, pp. 535-555, 1986.

[40] C. C. Stahlbaum and K. A. Houpt, "The role of the Flehmen response in the behavioral repertoire of the stallion," Physiology and Behavior, vol. 45, no. 6, pp. 1207-1214, 1989. 

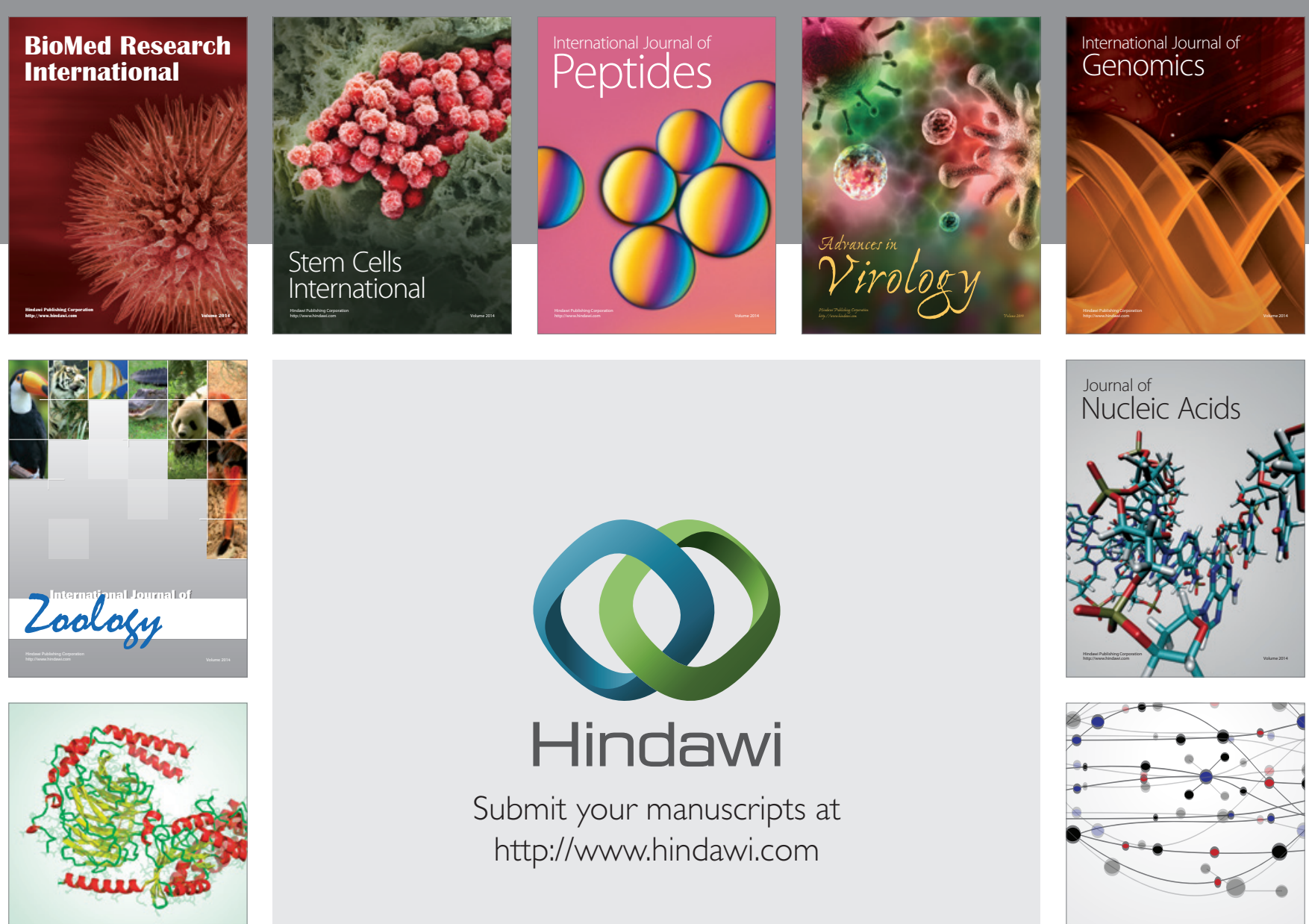

Submit your manuscripts at

http://www.hindawi.com

Signal ${ }^{\text {Jumal }}$ Transduction
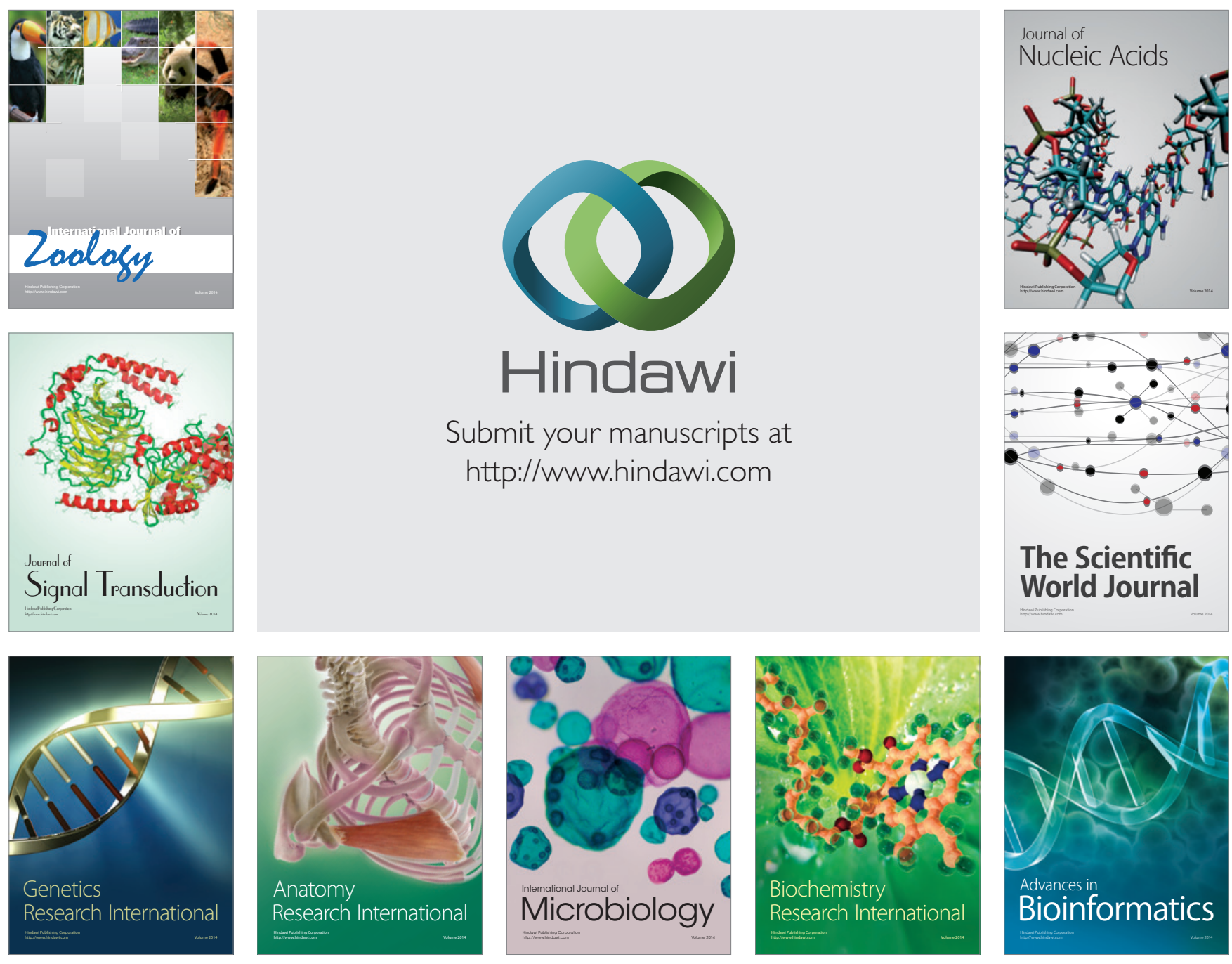

The Scientific World Journal
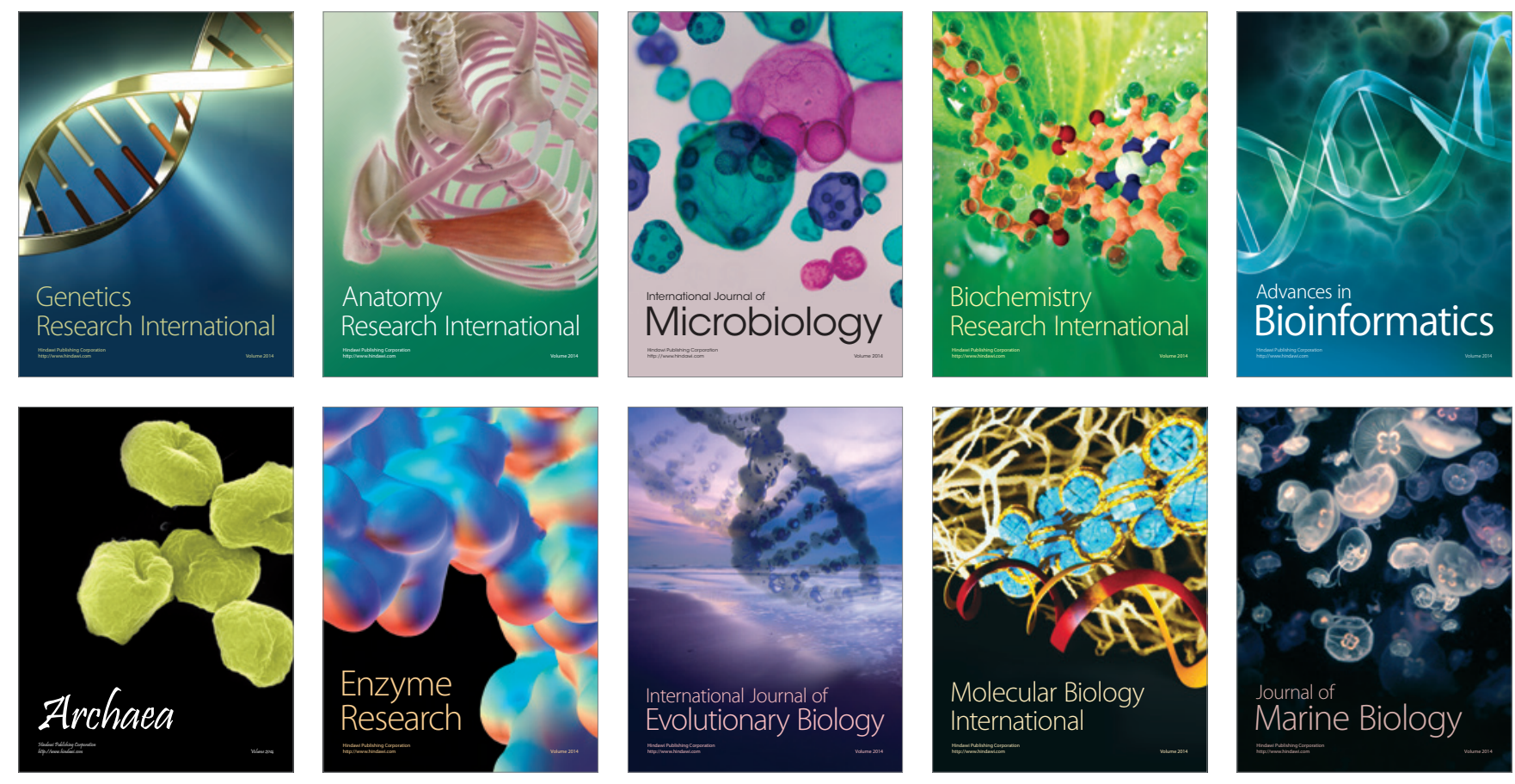